\title{
Ship-borne measurements of erythemal UV irradiance and ozone content in various climate zones
}

\author{
Sigrid Wuttke,* Saad El Naggar, Thaddäus Bluszcz and Otto Schrems
}

\author{
Received 4th December 2006, Accepted 13th July 2007 \\ First published as an Advance Article on the web 3rd September 2007 \\ DOI: 10.1039/b617602j
}

Ship-borne measurements of spectral as well as biologically effective UV irradiance have been performed on the German research vessel Polarstern during the Atlantic transect from Bremerhaven, Germany $\left(53.5^{\circ} \mathrm{N}, 8.5^{\circ} \mathrm{E}\right)$, to Cape Town, South Africa $\left(33.6^{\circ} \mathrm{S}, 18.3^{\circ} \mathrm{E}\right)$, from 13 October to 17

November 2005. Such measurements are required to study UV effects on marine organisms. They are also necessary to validate satellite-derived surface UV irradiance. Cloud free radiative transfer calculations support the investigation of this latitudinal dependence. Input parameters, such as total ozone column and aerosol optical depth have been measured on board as well. Using these measured parameters, the modelled cloudless noontime UVA irradiance (320-400 nm) shows the expected dependence on varying minimum solar zenith angles (SZA) at different latitudes. The modelled cloudless noontime UVB irradiance (290-320 nm) does not show this clear dependence on SZA due to the strong influence of ozone absorption in this spectral range. The maximum daily dose of erythemal irradiance of $5420 \mathrm{~J} \mathrm{~m}^{-1}$ was observed on 14 November 2005, when the ship was in the tropical Atlantic south of the equator. The expected UV maximum should have been observed with the sun in the zenith during local noon (11 November). Stratiform clouds reduced the dose to $3835 \mathrm{~J} \mathrm{~m}^{-1}$. In comparison, the daily erythemal doses in the mid-latitudinal Bay of Biscay only reached values between 410 and $980 \mathrm{~J} \mathrm{~m}^{-1}$ depending on cloud conditions. The deviation in daily erythemal dose derived from different instruments is around $5 \%$. The feasibility to perform ship-borne measurements of spectral UV irradiance is demonstrated.

\section{Introduction}

Increased levels of biologically harmful ultraviolet (UV) radiation have been proven to affect aquatic ecosystems, which respond even more sensitively to abiotic stressors such as enhanced UV radiation than terrestrial ones. ${ }^{1,2}$ Exposure to enhanced UVB $(290-320 \mathrm{~nm})$ radiation may result in a magnitude of biological effects on the molecular, cellular, individual, community and even on the ecosystem level. ${ }^{1}$ One important effect is a reduction in phytoplankton productivity caused by inhibition of photosynthesis, which not only constricts the marine food chain but also reduces the $\mathrm{CO}_{2}$ storage capability of the ocean. ${ }^{1,3}$ The primary production of macro algae communities, which are known to be amongst the most productive ecosystems on Earth, decreases due to enhanced UV levels as well. In such communities, a shift towards UV tolerant algae results and UV sensible organisms evade to greater depths. ${ }^{1,2,4,5}$

In order to investigate biological effects of changing radiation conditions on aquatic organisms and ecosystems, radiation data in a marine environment need to be available. Long term changes in incident solar radiation over land can differ in sign and magnitude from those over oceans. ${ }^{6}$ Information about surface UV levels over oceans can be obtained from satellite data in combination with radiative transfer models. ${ }^{7}$ These data need to be validated

Alfred Wegener Institute for Polar and Marine Research, Am Handelshafen 12, 27570, Bremerhaven, Germany. E-mail: Sigrid.Wuttke@awi.de; Fax: +49 471 4831-1149; Tel: +49471 4831-1411 with high quality ground-based measurements of UV irradiance, ${ }^{8}$ which are routinely performed over land but in situ measurements of biologically effective UV irradiance in a marine environment are sparse.

One way to overcome this problem is to perform ship-borne measurements of surface radiation parameters. An advantage of measurements on moving platforms such as a research vessel is that data can be obtained with the same instruments in different climate zones. Conducting measurements of radiation parameters on board a ship presents a greater challenge than over land. The ship moves constantly causing the radiation sensors not to be levelled horizontally. In addition, parts of the ship's superstructures limit the field of view of the radiation detectors. These two factors contribute to the overall uncertainty in the measured radiation parameters.

In this study we present ship-borne measurements of spectral UV irradiance and broadband erythemal UV irradiance measured by different types of sensors. These spectral as well as broadband measurements have been performed on the German research vessel Polarstern during an Atlantic transect from Bremerhaven, Germany, to Cape Town, South Africa, from 13 October to 17 November 2005 and covered latitude between $54^{\circ} \mathrm{N}$ and $38^{\circ} \mathrm{S}$.

Different climate zones including the tropics have been crossed. This way it is possible to assess various UV radiation conditions as a function of latitude, solar zenith angle (SZA) and total ozone column. To investigate the influence of ozone, especially the natural ozone minimum in the tropics, ballone-borne ozone sondes have been launched daily. Further the feasibility of ship-borne 
measurements of broadband as well as spectral UV radiation will be discussed.

\section{Materials and methods}

The data collected during the cruise are checked with different quality control procedures. These include initial comparisons of the different radiation sensors, comparisons to a radiative transfer model for cloud free occasions, or the investigation of diurnal cycles of erythemal irradiance.

\section{Spectral UV irradiance}

Solar spectral UV irradiance is recorded with the UV-spectrometer of the Alfred Wegener Institute for Polar and Marine Research (AWI). ${ }^{9}$ This instrument consists of a Bentham 150 DTM double monochromator with a 32 multi channel photomultiplier plate to measure UVB irradiance (290 to $320 \mathrm{~nm}$ ). The single channels of the UVB instrument are $1.35 \mathrm{~nm}$ apart and the resolution is about $2 \mathrm{~nm}$. To detect UVA irradiance (320 to $400 \mathrm{~nm}$ ) an Oriel single monochromator with 256 diode array detector is used. This instrument has a resolution of $2 \mathrm{~nm}$. The channels have a step width of only $0.65 \mathrm{~nm}$. Both parts of the AWI-UV-spectrometer are operated in a temperature stabilised box. The temperature is stable within $\pm 1 \mathrm{~K}$. The UVA and UVB spectroradiometers are driven by a common software.

The AWI-UV-spectrometer was set up on the upper deck on the starboard side of $R / V$ Polarstern. It was operated in a continuous modus, thus spectra of UV irradiance have been recorded day and night. They have been stored every minute.

During the cruise, the radiometric stability, the wavelength alignment, and the dark current of the spectroradiometer have been tested on a regular basis. The stability tests are performed with a $150 \mathrm{~W}$ tungsten halogen lamp which is incorporated in a mobile calibration unit. ${ }^{10}$ This $150 \mathrm{~W}$ lamp is traceable to the primary standard of the Physikalisch Technische Bundesanstalt (PTB), Germany. The wavelength alignment is tested with a low pressure mercury lamp.

To finally calculate absolute values of spectral irradiance, the following uncertainties have to be taken into account: change in radiometric stability, ${ }^{11}$ possible wavelength shifts, ${ }^{12}$ correction for the deviation of the input optics from the ideal cosine response, ${ }^{13}$ shadowing effects of the ship's superstructures, and the ship's movements.

\section{Broadband erythemal UV irradiance}

Erythemal irradiance is recorded by two different types of instruments: the personal UVB-dosimeter ELUV-14, ${ }^{14}$ and the Solar Light Model 501 Biometer. Both instruments are broadband detectors with a response similar to the erythemal action spectrum. Data are stored in daily files in 1 minute and 5 minute records for the ELUV dosimeters and the Biometer, respectively. These two different types of broadband sensors have been used for different reasons: The ELUV-sensor is used frequently by a group of biologists investigating UV effects on algae. ${ }^{15}$ The SL501 is an internationally recognised radiometer to measure erythemally weighted irradiance. ${ }^{16}$

\section{Ozone}

Ozone profiles are determined with balloon borne electrochemical (ECC) ozone sondes. ${ }^{17}$ The ozone sensor is coupled via an interface to a meteorological radio sonde, model RS 92 from VAISALA. This way, the vertical distribution of ozone, temperature and humidity in the atmosphere can be measured. Such a balloon is launched every day. Data is transmitted by the radio sonde at a predetermined frequency every 5 seconds. These types of balloon-borne ozone measurements are also implemented in the Global Atmosphere Watch (GAW) programme of the World Meteorological Organization (WMO). ${ }^{18}$ The accuracy of these types of sensors is around $\pm 5 \%$ in the stratosphere. ${ }^{19}$

During conditions with direct sun, the total ozone column is measured by a portable Solar Light Microtops Ozonometer. This hand held instrument is a portable sun photometer with three channels $(305,312,320 \mathrm{~nm})$ for the detection of total ozone column. This type of instrument has been compared to Dobson and Brewer spectrometers at the Meteorological Observatory Hohenpeissenberg, Germany. The agreement between the Microtops and the recognized spectrometers has found to be better than $\pm 1 \%$ for most airmasses. Adverse observing conditions lead to deviations up to $\pm 3 \% .{ }^{20}$ Due to its easy handling, the Microtops has previously been applied for various studies concerning the UV radiation environment. ${ }^{21,22}$

\section{Ancillary data}

A range of meteorological instruments are operated on $R / V$ Polarstern (http://www.awi.de/en/infrastructure/ships/ polarstern/meteorological_observatory/). For this study, the global irradiance collected with a Kipp \& Zonen CM11 pyranometer, the sunshine indication detected by a SONI e3 sensor, the cloud base height measured with a Laser Ceilograph by Impulsphysik $\mathrm{GmbH}$, and the visibility determined with a LD-WHX05 sensor by Impulsphysik $\mathrm{GmbH}$ are exploited. These data are stored in the PODAS database (http://podas.awi-bremerhaven.de/). Besides the meteorological parameters, the location, the ship's heading, pitch and roll are also available. A weather observation has been carried out every three hours between 6 UTC and 21 UTC by a technician of the German Weather Service (DWD). This observation includes the determination of the cloud coverage and cloud type as well as the sea state.

\section{Radiative transfer calculations}

The freely available library for radiative transfer calculations LibRadtran $^{23}$ was used to calculate spectral irradiance at the surface. The use of model calculations will yield a quantification of the attenuation of incident UV radiation by clouds.

The most important input parameters comprise the solar zenith angle (SZA), the total ozone column, surface albedo and a default aerosol parameterisation. The SZA was calculated according to the position of the ship and the time referring to the measured spectra. The total ozone column is derived from the ozone profiles obtained from the launches of the ECC ozone sondes because they have been available on a daily basis. The albedo was considered to be constant with 0.2 and a default aerosol parameterisation for a marine environment has been used, except for the visibility, which was taken from the routine measurements with the LD-WHX05. 
Vertical profiles of air pressure, temperature, ozone and water vapor distribution measured by the balloon-borne meteorological and ozone sondes have been included in the radiative transfer calculations as well. The model calculations do not include clouds.

\section{Results}

\section{Radiation conditions}

To describe the radiation climate on this voyage, the noon time UVB and UVA irradiance in dependence of latitude are shown in Fig. 1 and 2, respectively. The UVB integral comprises the wavelength range from 290 to $320 \mathrm{~nm}$. The UVA integral has boundaries from 320 to $400 \mathrm{~nm}$. These noon time integrals are derived from the measurements of spectral UV irradiance as well as from radiative transfer calculations (see previous section). The modelled cloudless noontime UVA irradiance shows the expected dependence on different midday solar zenith angles at different latitudes. The modelled cloudless noontime UVB irradiance does not show this clear dependence on SZA due to the strong influence of ozone absorption in this spectral range. The varying deviations of the measured and modelled UVA and UVB irradiance are due to the presence of clouds. It can be seen in Fig. 1 that the absolute UVB irradiance is about one order of magnitude lower than the UVA irradiance (see Fig. 2). However, the biological effectiveness is much higher in the UVB. Therefore, it is the wavelength region of interest for a number of UV effects studies.

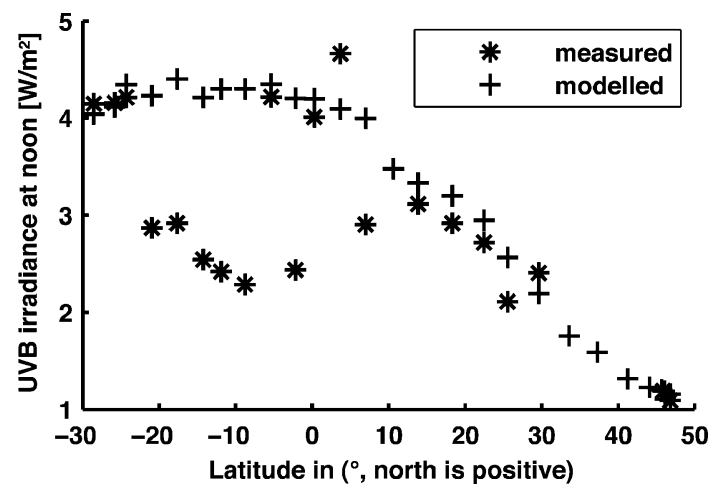

Fig. 1 Midday UVB irradiance in dependence of latitude as measured on R/V Polarstern between 13 October and 17 November 2005.

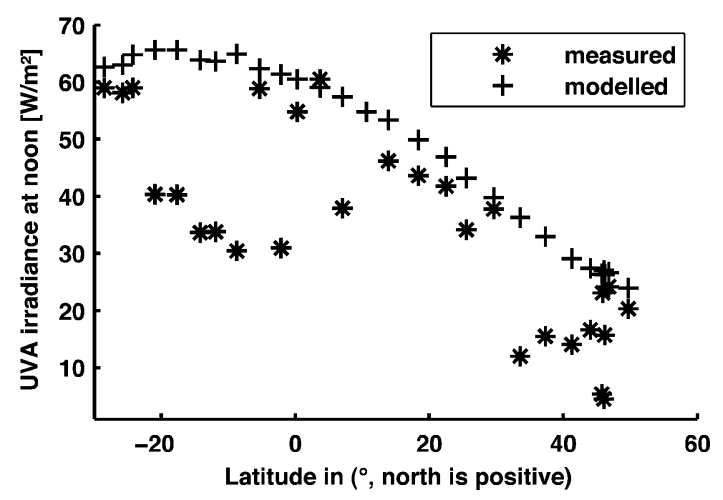

Fig. 2 Midday UVA irradiance in dependence of latitude as measured on $R / V$ Polarstern between 13 October and 17 November 2005.
To emphasise the biological effectiveness the daily doses of erythemal UV irradiation is shown in Fig. 3. Instead of the maximal noon time values, it was chosen to show the daily doses, because the impact of incident radiation on living organisms not only depends on maximal radiation levels but even more on the sum of incident radiation. This effect is best described by daily doses. The daily doses shown in Fig. 3 are measured by different radiation detectors (see "Materials and methods") with slightly different response functions. The maximum daily dose of erythemal irradiation with $5420 \mathrm{~J} \mathrm{~m}^{-1}$ was observed on 14 November 2005. On this day the ship was in the sub-tropical Atlantic south of the equator $\left(26^{\circ} \mathrm{S}\right)$. The expected UV maximum should have been observed on 11 November $2005\left(17.8^{\circ} \mathrm{S}\right)$ because this was the day with minimal SZA $\left(0.1^{\circ}\right)$ during local noon. However, a stratiform cloud cover prevented the dose from being maximal reducing it to $3835 \mathrm{~J} \mathrm{~m}^{-1}$. In comparison, the daily doses of erythemal irradiance in the mid-latitudinal Bay of Biscay only reached values between 410 and $980 \mathrm{~J} \mathrm{~m}^{-1}$ depending on cloud conditions. The deviation in daily erythemal dose derived from different instruments is in the order of $5 \%$.

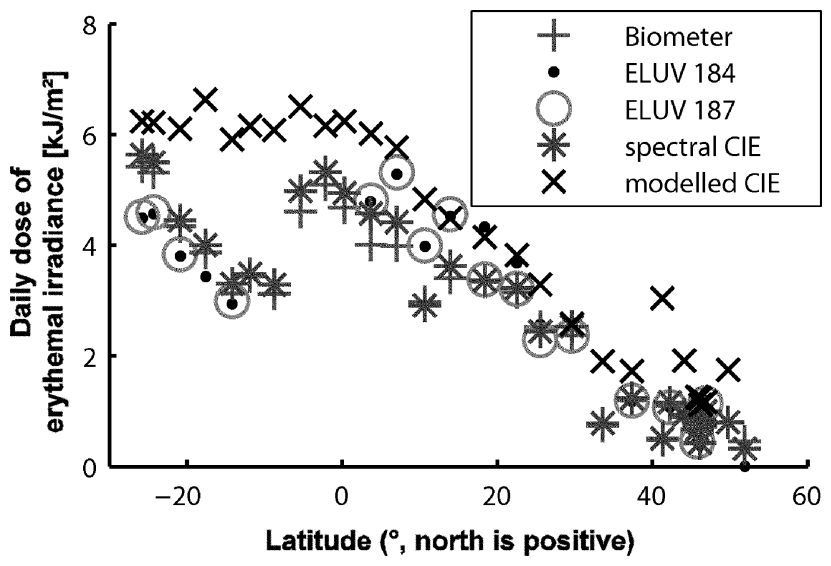

Fig. 3 Daily dose of erythemal irradiance in dependence of latitude as measured on $R / V$ Polarstern between 13 October and 17 November 2005.

\section{Agreement between different sensors}

The diurnal cycle of erythemal irradiance measured by different sensors as well as the modelled erythemal irradiance for 28 October 2005 is shown in the upper panel of Fig. 4. This was the day with the least occurrence of clouds during the Atlantic transect. The cloud observations detected only one octa of cumulus or stratocumulus during daylight hours. The SONI e3 sensor detected sunshine from 11:30 UTC. During the morning hours, the direct beam of the sun was temporarily blocked. This can be seen in all measured erythemal irradiance values. They deviate from the modelled diurnal cycle, which does not include clouds. The erythemal irradiance measured by the ELUV-14 sensor is higher than the values measured by the other instruments. This is due to the instrumental response of the ELUV sensors, which slightly deviates from the erythemal action spectrum. The erythemal irradiance derived from the spectral UV data deviates up to $\pm 12 \%$ from the model results during the nearly cloudless periods (see lower panel of Fig. 4). For large SZA, the erythemal irradiance measured with the Biometer is underestimated compared to the modelled erythemal irradiance and the erythemal irradiance 


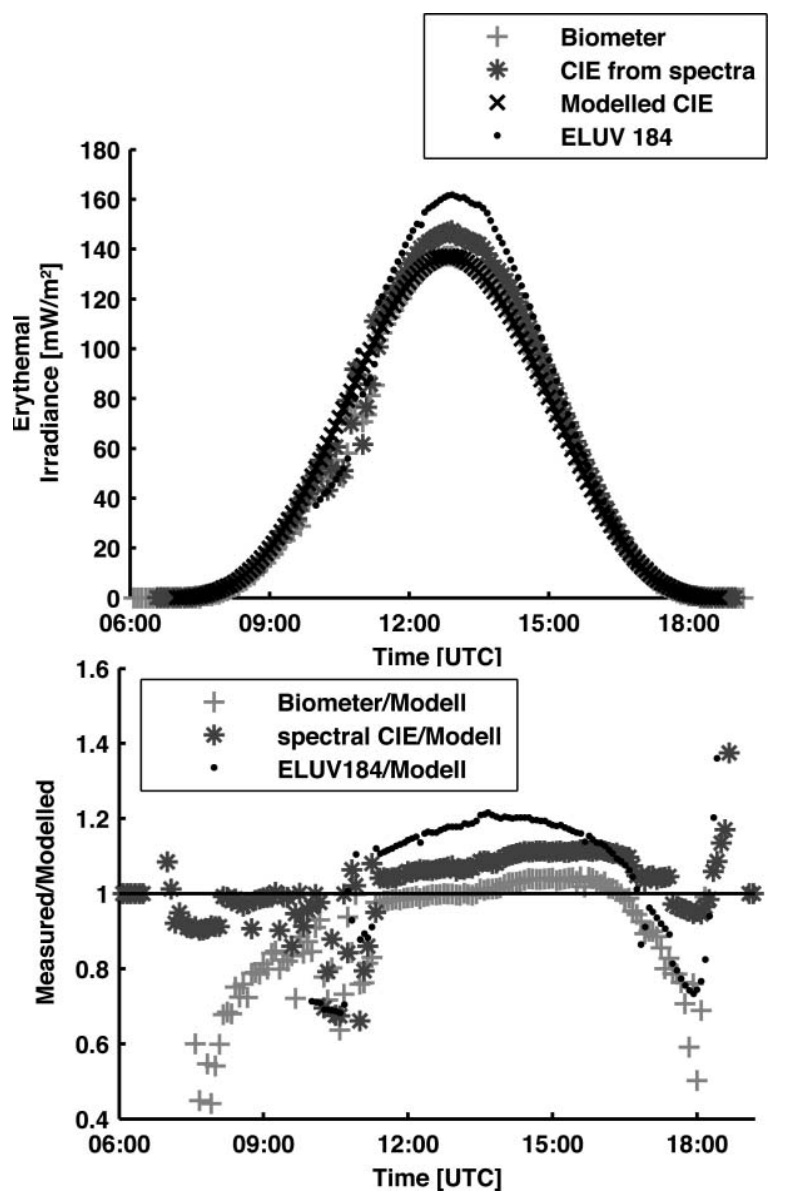

Fig. 4 Upper panel: measured and modelled diurnal cycle of erythemal irradiance on 28 October 2005. Lower panel: ratio of measured erythemal irradiance to the cloudless model. The deviation between the Biometer and the erythemal irradiance derived from spectral data deviates less than $12 \%$ from the model between 11:30 and 17:30 UTC.

derived from the spectral data. This indicates a deviation from the ideal cosine response.

\section{Ozone}

Ozone sounding using ECC-sondes in combination with VAISALA RS-92-SGP radio sondes was successfully carried out on a daily basis between 15 October and 15 November 2005. A total of 29 ozone profiles were recorded. In addition, total ozone columns have been recorded with the Microtops ozonometer whenever the sun was not obscured by clouds. On different days the profiles were recorded between 8:30 and 16:30 UTC. On most days more than one Microtops ozone column was recorded. In this case a mean ozone column of the recorded values has been displayed in Fig. 5. Fig. 5 shows the latitudinal distribution of the total ozone column derived from both instruments.

The total ozone column was 327 Dobson Units (DU) in the north on 18 October 2005. It decreased to 249 DU just north of the equator on 3 November 2005. Between 2 and 5 November 2005 we crossed the innertropical convergence zone (ITCZ), where the tropical ozone minimum is expected. The total ozone column increased again south of the ITCZ to 319 DU on 15 November 2005.

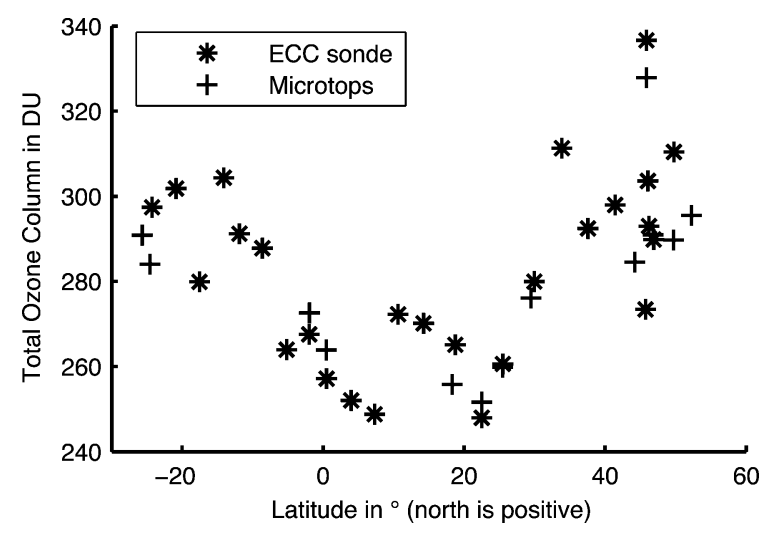

Fig. 5 Total ozone column in Dobson Units as derived from the ECC sondes and the Microtops in dependence of latitude measured on $R / V$ Polarstern between 13 October and 17 November 2005.

Two ozone profiles are shown in Fig. 6. One profile was measured on 16 October 2005 in the northern hemisphere, north of the ITCZ. The profile on 9 November 05 was measured south of the equator and the ITCZ. The stratospheric ozone maximum can be observed in both profiles. As expected, this ozone layer is at a higher altitude in the tropics compared to the mid-latitudes. On both days the total ozone column was roughly the same, with 290 DU and 291 DU on 16 October and 9 November, respectively.

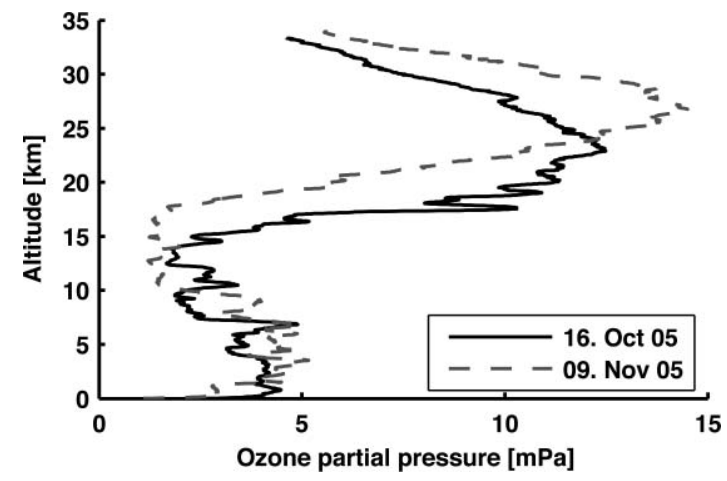

Fig. 6 Two ozone profiles derived from the ECC sondes. On 16 October $R / V$ Polarstern was situated at $46.9^{\circ} \mathrm{N}$ with a total ozone column of 290 DU. On 9 November the vessel was at $11.9^{\circ} \mathrm{S}$. The total ozone column was $291 \mathrm{DU}$

\section{SZA and clouds}

Table 1 provides an overview of the cloud conditions during ANT $\mathrm{XXIII/1.} \mathrm{The} \mathrm{cloud} \mathrm{cover} \mathrm{is} \mathrm{given} \mathrm{as} \mathrm{well} \mathrm{as} \mathrm{the} \mathrm{type} \mathrm{of} \mathrm{low,}$ medium and high clouds taken from the weather observations at 12:00 UTC. To indicate whether the sun was obscured by clouds during noon, the results of the SONI e3 sensor are displayed as well. The cloud modification factor (CMF) indicates the cloud attenuation of the incident UVB and UVA radiation. The CMF is defined as the ratio between the actually measured UV irradiance $\left(E_{\text {meas }}\right)$ and the modelled cloud free UV irradiance ${ }^{24}\left(E_{\text {mod }} ; \mathrm{CMF}=\right.$ $\left.E_{\text {meas }} / E_{\text {mod }}\right)$. The CMF is always lower for the UVA compared to the UVB. A CMF larger than 1 occurs for example on 28 October and 4 November. On these occasions, the sun was not obscured by clouds. It can further be seen from Table 1 that the CMF does not 
Table 1 Cloud modification factors (CMF) for UVB and UVA for noontime irradiance values and cloud observations at 12:00 UTC

\begin{tabular}{|c|c|c|c|c|c|c|c|c|}
\hline $\begin{array}{l}\text { Date/latitude } \\
\text { at noon }{ }^{\circ}\end{array}$ & $\mathrm{SZA} /{ }^{\circ}$ & CMF UVB & CMF UVA & $\begin{array}{l}\text { Cloud } \\
\text { cover/octas }\end{array}$ & $\begin{array}{l}\text { Low clouds } \\
(\mathrm{CL})^{a}\end{array}$ & $\begin{array}{l}\text { Medium clouds } \\
(\mathrm{CM})^{b}\end{array}$ & $\begin{array}{l}\text { High clouds } \\
(\mathrm{CH})^{c}\end{array}$ & $\begin{array}{l}\text { Sunshine } \\
\text { indication }^{d}\end{array}$ \\
\hline $15.10 . / 49.7$ & 58.4 & 0.89 & 0.85 & 2 & 0 & 0 & 2 & $\mathrm{n} / \mathrm{a}$ \\
\hline $16.10 . / 46.8$ & 55.8 & 0.94 & 0.85 & 1 & 0 & 0 & 1 & 1 \\
\hline $17.10 . / 46.1$ & 55.5 & 0.19 & 0.17 & 8 & 5 & 7 & & 0 \\
\hline $18.10 . / 45.9$ & 55.6 & $\mathrm{n} / \mathrm{a}$ & $\mathrm{n} / \mathrm{a}$ & 6 & 2 & 0 & 1 & 1 \\
\hline $19.10 . / 46.2$ & 56.3 & 0.77 & 0.60 & 5 & 8 & 3 & 1 & 0 \\
\hline $20.10 . / 45.7$ & 56.2 & 0.24 & 0.20 & 7 & 8 & & & 0 \\
\hline $21.10 . / 45.9$ & 56.7 & $\mathrm{n} / \mathrm{a}$ & $\mathrm{n} / \mathrm{a}$ & 6 & 2 & 0 & 1 & 1 \\
\hline $22.10 . / 44.1$ & 55.3 & 0.78 & 0.61 & 2 & 8 & 0 & 0 & 0 \\
\hline $23.10 . / 42.2$ & 53.8 & $\mathrm{n} / \mathrm{a}$ & $\mathrm{n} / \mathrm{a}$ & $\mathrm{n} / \mathrm{a}$ & $\mathrm{n} / \mathrm{a}$ & $\mathrm{n} / \mathrm{a}$ & $\mathrm{n} / \mathrm{a}$ & 1 \\
\hline $24.10 . / 42.2$ & 54.1 & $\mathrm{n} / \mathrm{a}$ & $\mathrm{n} / \mathrm{a}$ & $\mathrm{n} / \mathrm{a}$ & $\mathrm{n} / \mathrm{a}$ & $\mathrm{n} / \mathrm{a}$ & $\mathrm{n} / \mathrm{a}$ & 0 \\
\hline $25.10 . / 41.3$ & 53.6 & 0.58 & 0.48 & 8 & 6 & & & 0 \\
\hline $26.10 . / 37.3$ & 50.0 & 0.57 & 0.47 & 7 & 5 & & & 0 \\
\hline $27.10 . / 33.6$ & 46.7 & 0.41 & 0.33 & 8 & 8 & 2 & & 0 \\
\hline $28.10 . / 29.6$ & 43.1 & 1.10 & 0.95 & 1 & 0 & 0 & 1 & 1 \\
\hline $29.10 . / 25.5$ & 39.3 & 0.82 & 0.79 & 3 & 1 & 0 & 0 & 0 \\
\hline $30.10 . / 22.5$ & 36.4 & 0.92 & 0.89 & 5 & 1 & 0 & 0 & 1 \\
\hline $31.10 . / 18.4$ & 32.8 & 0.91 & 0.87 & 4 & 1 & 0 & 0 & 1 \\
\hline $1.11 . / 13.9$ & 28.7 & 0.94 & 0.86 & 4 & 5 & 0 & 1 & 1 \\
\hline $2.11 . / 10.6$ & 25.5 & $\mathrm{n} / \mathrm{a}$ & $\mathrm{n} / \mathrm{a}$ & 7 & 8 & 0 & 2 & 0 \\
\hline $3.11 . / 7.0$ & 22.4 & 0.73 & 0.66 & 5 & 9 & 0 & 2 & 1 \\
\hline $4.11 . / 3.7$ & 19.4 & 1.14 & 1.02 & 6 & 9 & 3 & 2 & 1 \\
\hline $5.11 . / 0.3$ & 16.2 & 0.95 & 0.91 & 3 & 8 & 3 & 1 & 1 \\
\hline $6.11 . /-2.1$ & 14.1 & 0.58 & 0.50 & 5 & 2 & 0 & 0 & 0 \\
\hline $7.11 . /-5.4$ & 11.1 & 0.97 & 0.94 & 5 & 8 & 3 & 0 & 0 \\
\hline $8.11 . /-8.8$ & 8.0 & 0.53 & 0.47 & 7 & 5 & & & 0 \\
\hline $9.11 . /-11.9$ & 5.1 & 0.56 & 0.53 & 7 & 8 & & & 0 \\
\hline $10.11 . /-14.2$ & 3.1 & 0.60 & 0.53 & 7 & 5 & & & 0 \\
\hline $11.11 . /-17.7$ & 3.2 & 0.66 & 0.61 & 7 & 5 & & & 0 \\
\hline $12.11 . /-20.9$ & 3.1 & 0.68 & 0.61 & 7 & 5 & & & $\mathrm{n} / \mathrm{a}$ \\
\hline $13.11 . /-24.3$ & 6.2 & 0.97 & 0.91 & $\mathrm{n} / \mathrm{a}$ & $\mathrm{n} / \mathrm{a}$ & $\mathrm{n} / \mathrm{a}$ & $\mathrm{n} / \mathrm{a}$ & $\mathrm{n} / \mathrm{a}$ \\
\hline $14.11 . /-25.8$ & 7.4 & 1.01 & 0.92 & 3 & 8 & 0 & 0 & $\mathrm{n} / \mathrm{a}$ \\
\hline $15.11 . /-28.5$ & 9.9 & 1.03 & 0.94 & 1 & 8 & 0 & 1 & $\mathrm{n} / \mathrm{a}$ \\
\hline
\end{tabular}

${ }^{a}$ Numbers represent the following cloud categories of low clouds: 0 no stratocumulus, stratus, cumulus or cumulonimbus; 1 cumulus with little vertical extent and seemingly flattened, or ragged cumulus other than of bad weather, or both; 2 cumulus of moderate or strong vertical extent, generally with protuberances in the form of domes or towers, either accompanied or not by other cumulus or by stratocumulus, all having their bases at the same level; 5 stratocumulus not formed from the spreading out of cumulus; 6 stratus in a more or less continuous sheet or layer, or in ragged shreds, or both, but no stratus fractus of bad weather; 8 cumulus and stratocumulus other than that formed from the spreading out of cumulus; the base of the cumulus is at a different level from that of the stratocumulus; 9 cumulonimbus, the upper part of which is clearly fibrous (cirriform), often in the form of an anvil; either accompanied by cumulonimbus without anvil or fibrous upper part, by cumulus, stratocumulus, stratus or pannus; blank no observation possible. ${ }^{b}$ Numbers represent the following categories of medium high clouds: 0 no altocumulus, altostratus or nimbostratus; 2 altostratus, the greater part of which is sufficiently dense to hide the sun or moon, or nimbostratus; 3 altocumulus, the greater part of which is semi-transparent; the various elements of the cloud change only slowly and are all at a single level; 7 altocumulus in two or more layers, usually opaque in places, and not progressively invading the sky; or opaque layer of altocumulus, not progressively invading the sky; or altocumulus together with altostratus or nimbostratus; blank altocumulus, altostratus and nimbostratus invisible owing to darkness, fog, blowing snow, dust or sand, or other similar phenomena, or more often because of the presence of a continuous layer of lower clouds. ${ }^{c}$ Numbers represent the following categories of high clouds: 0 no cirrus, cirrocumulus or cirrostratus; 1 cirrus in the form of filaments, strands or hooks, not progressively invading the sky; 2 dense cirrus, in patches or entangled sheaves, which usually do not increase and sometimes seem to be the remains of the upper part of a cumulonimbus; or cirrus with sproutings in the form of small turrets or battlements, or cirrus having the appearance of cumuliform tufts; blank cirrus, cirrocumulus or cirrostratus invisible owing to darkness, fog, blowing snow, dust or sand, or other similar phenomena, or more often because of the presence of a continuous layer of lower clouds. ${ }^{d} 0$ indicates obscured sun, 1 indicates direct sun.

depend on SZA. High CMFs are observed at various latitudes in the northern and southern hemisphere.

During this voyage, the absolutely highest UVB and UVA irradiances are observed on 4 November at $3.7^{\circ} \mathrm{N}$ (see Fig. 1 and 2). The highest erythemal irradiance was measured with the SL 501 biometer on 13 November at $24.3^{\circ} \mathrm{S}$ (see Fig. 3).

\section{Discussion}

The first part of the discussion deals with the feasibility of ship-borne radiation measurements with emphasis on the ship's pitch and roll as well as the shadowing effect of the ship's superstructures. Further, the impact of the SZA, clouds, and ozone column influencing the UV radiation at the surface will be discussed.

\section{Feasibility of ship-borne radiation measurements}

The methodological uncertainty introduced in the measurements of spectral and erythemal irradiance due to the ship's movements as well as the shadowing effect of the ship's superstructures have to be discussed because it is not trivial to perform radiation measurements on a moving platform such as a ship. 


\section{Ship's pitch and roll}

It is assumed that the uncertainty introduced due to the ship's movement has the same effect as a mislevelled sensor or as an azimuthal error of the instrument. For small deviations of the sensor plane from the horizontal, it can further be assumed that the diffuse portion of the incident radiation is not affected by the tilt. Thus, eqn (1) is used to calculate the ratio between irradiance incident on a tilted to an untilted surface ${ }^{16}$

$$
r=[\mathrm{Dif}+\operatorname{Dir} \times \cos (\mathrm{SZA}-\alpha) / \cos (\mathrm{SZA})] /[\mathrm{Dif}+\mathrm{Dir}]
$$

where Dif is the diffuse irradiance, Dir the direct irradiance, and $\alpha$ is the angle between the horizontal and the tilted surface.

At $400 \mathrm{~nm}$ and a solar zenith angle of $0^{\circ}$, the contribution of the direct irradiance to the global irradiance is largest with a value of roughly $60 \%$. With decreasing wavelength and increasing SZA, the proportion of direct irradiance decreases. At $300 \mathrm{~nm}$ and an SZA of $0^{\circ}$ it is around $30 \%$. At an SZA of $70^{\circ}$, the direct irradiance contributes less than $5 \%$ to the global irradiance for all wavelengths in the ultraviolet.

This low fraction of direct irradiance together with the assumption that only the direct irradiance is affected by the tilted sensor leads to a deviation of erythemal irradiance incident on a tilted compared to a horizontal surface of less than $1 \%$ as long as $\alpha$ is lower than $2^{\circ}$.

Due to the calm weather conditions during the cruise, the maximum ship's pitch and roll was less than $10^{\circ}$ at all times. It takes $17 \mathrm{~s}$ for the ship to accomplish one pitch or roll cycle. This means that the ship's movements are much faster than the sampling time of the radiation detectors, which record one value or one spectrum every minute. Thus, the detected irradiance resembles a mean irradiance incident on a surface with different deviations from the horizontal. To determine the effective tilt for each minute of data sampling the minutely minimal and maximal pitch and roll angles have been extracted from the PODAS database. The average of these extreme pitch and roll values is the effective tilt of the sensor during a one-minute interval. To estimate the deviation of the incident erythemal irradiance from the horizontal, this effective angle has been used as $\alpha$ in eqn (1). For the whole cruise, the mean pitch was $(0.14 \pm 0.32)^{\circ}(2 \sigma)$ and the mean roll was $(-0.13 \pm 1.44)^{\circ}$ $(2 \sigma)$. Thus, $95 \%$ of the mean maximum pitch or roll was lower than $2^{\circ}$. This means that the deviation in erythemal irradiance from a perfectly aligned horizontal surface is less than $1 \%$, which can be neglected.

\section{Ship's superstructures}

To find an ideal spot to set up a spectroradiometer on a ship is nearly impossible. There are always superstructures such as antennas or platforms obscuring part of the sky. For some situations these superstructures block the direct beam of the sun.

On this cruise, the radiation detectors have been set up on the starboard side of the second upper most deck. This spot was a compromise between an obscured horizon and the instruments being protected from possible droplets of sea spray. Even at the chosen set-up spot the quartz domes of the entrance optics needed to be cleaned every morning before sunrise and every evening after sunset due to few sea spray deposits.
In the middle of this deck, there is a big platform. The height and width of the platform as well as the distance to the radiation sensors is known. So, the part of the sky covered by the platform can be calculated. It amounts to $9.5 \%$ of the whole sky dome. The erythemal irradiance is considered to be isotropically distributed across the sky. ${ }^{25-27}$ The platform obstructs the diffuse irradiance between an elevation angle between $0^{\circ}$ and $60^{\circ}$. When measuring irradiance, the incident radiance is weighted with the cosine of the solar zenith angle. Thus, the contribution of radiance obscured by the platform is reduced to about $5 \%$ of the diffuse irradiance. This would be valid if the superstructures of the ship had a reflectance of 0 . It was not possible to determine the reflectivity of the ship's superstructures. Therefore, the diffuse part of the erythemal irradiance has not been corrected for this effect. For future cruises, it is recommended to determine the reflectivity of the superstructures in order to find the correction factor to account for the shadowing effect of the ship's superstructures. During the periods, when the direct beam of the sun was blocked by the ship's superstructures, the measured erythemal as well as spectral irradiance has been excluded from the data analysis.

\section{Effect of SZA, clouds and ozone}

In contrast to the methodological uncertainties, the impact of SZA, clouds and ozone as main influencing parameters of UV radiation reaching the surface ${ }^{28}$ has to be assessed.

The influence of ozone and clouds is wavelength dependent. Ozone strongly absorbs in the UVB part of the solar spectrum. It is more absorbing the shorter the wavelength. The wavelength dependence of clouds is not as pronounced. For a homogenous cloud layer at $1200 \mathrm{~m}$ in midlatitudes the cloud transmittance was found to be $45 \%$ in the UVA and $60 \%$ in the UVB. ${ }^{29}$ This wavelength dependence is explained by photons scattered upwards from the cloud and then scattered downward again, effectively trying to make it through the cloud more than once. The number of photons this happens to is a function of the wavelength dependent Rayleigh scattering and ozone absorption cross sections. ${ }^{30}$ This is also the explanation for the CMF always being smaller in the UVA compared to the UVB (see Table 1) meaning that the transmission of radiation is weaker in the UVA. The observed CMFs range from 0.19 to 1.14 in the UVB and from 0.17 to 1.02 in the UVA. Situations with thick clouds have also been encountered like occasions with enhancement of UV radiation due to scattered clouds. Only true clear sky cases have very rarely been observed.

Fig. 7 shows the dependence of the normalised measured and modelled UVA and UVB irradiance on $\cos (\mathrm{SZA})$. The modelled irradiance do not include clouds. Thus, the difference between the measured and modelled irradiance resembles the cloud attenuation. Strong cloud attenuation has been observed with $\cos (\mathrm{SZA})$ between 0.5 and 0.6 , thus in the midlatitudes as well as in the ITCZ $(\cos (\mathrm{SZA})$ between 0.9 and 1$)$. But note that the normalised measured noontime irradiance in the ITCZ is higher, despite the thick clouds, compared to the modelled cloud free noontime irradiance with $\cos (\mathrm{SZA})$ lower than 0.6 .

The total ozone column derived from the two ozone profiles shown in Fig. 6 is nearly the same. On 16 October 2005 at $46.8^{\circ}$ $\mathrm{N}$ it amounts to $290 \mathrm{DU}$, and on 9 November $2005\left(11.9^{\circ} \mathrm{S}\right)$ it is 291 DU. The total ozone column should have the same effect on the absolute irradiance measured on both days. Thus, the influence 
Table 2 Comparison of UVA and UVB irradiance with the same total ozone column, but different SZA and cloud conditions. Note that the measured irradiance with SZA $=5.1^{\circ}$ is larger than the cloudless modelled irradiance with SZA $=55.8^{\circ}$. Thus, the SZA has the largest effect on the UV irradiance at the surface

\begin{tabular}{llllll}
\hline Latitude & $\begin{array}{l}\mathrm{SZA} \text { at noon/ } \\
\cos (\mathrm{SZA})\end{array}$ & $\begin{array}{l}\mathrm{UVA} / \mathrm{W} \mathrm{m}^{-1} \\
\text { measured at noon }\end{array}$ & $\begin{array}{l}\mathrm{UVB} / \mathrm{W} \mathrm{m}^{-1} \\
\text { measured at noon }\end{array}$ & $\begin{array}{l}\text { Cloudless UVA/W m } \\
\text { modelled at noon }\end{array}$ & $\begin{array}{l}\mathrm{Cloudless} \mathrm{UVB/W} \mathrm{m}^{-1} \\
\text { modelled at noon }\end{array}$ \\
\hline $11.9^{\circ} \mathrm{S}$ & $5.1^{\circ} / 0.99$ & 34.6 & 2.4 & 63.3 & 4.2 \\
$46.8^{\circ} \mathrm{N}$ & $55.8^{\circ} / 0.56$ & 24.3 & 1.1 & 26.9 & 1.2 \\
\hline
\end{tabular}

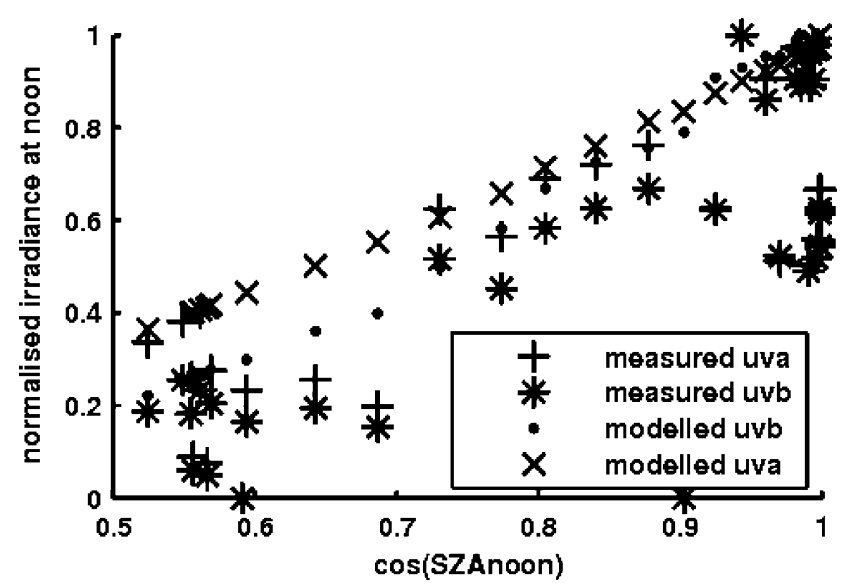

Fig. 7 Measured and modelled normalised noontime irradiance in dependence of $\cos (\mathrm{SZA})$.

of clouds and SZA can be looked at closer on these two occasions (see Table 2). The modelled UVA and UVB irradiances do not include clouds, leaving the SZA as the main influencing factor. With a SZA of $5.1^{\circ}(\cos (\mathrm{SZA})=0.56)$ at noon, the modelled UVA and UVB irradiances are 2.25 and 3.5 times as high compared to a SZA of $55.8^{\circ}(\cos (\mathrm{SZA})=0.99)$, respectively (see Fig. 7 and Table 2). According to the cloud observation at 12 UTC, one octa of cumulus humilis was present on 16 October at $46.8^{\circ}$ $\mathrm{N}$, whereas five octas of cumulunimbus with thick cirrus clouds prevailed on 9 November at $11.9^{\circ} \mathrm{S}$. Despite the thick clouds at $11.9^{\circ} \mathrm{S}\left(\mathrm{SZA}=5.1^{\circ}\right)$, the measured UVA and UVB irradiance is still higher compared to $46.9^{\circ} \mathrm{N}\left(\mathrm{SZA}=55.8^{\circ}\right)$. And note, that the measured UVA $\left(34.6 \mathrm{~W} \mathrm{~m}^{-1}\right)$ and UVB $\left(2.4 \mathrm{~W} \mathrm{~m}^{-1}\right)$ irradiance under a SZA of $5.1^{\circ}$, although affected by thick clouds, is larger than the modelled cloud free irradiance with a SZA of $55.8^{\circ}$ (UVA $=26.9 \mathrm{~W} \mathrm{~m}^{-1}$, UVB $=1.2 \mathrm{~W} \mathrm{~m}^{-1}$ ). This result underlines the fact that the SZA has a very strong influence on the absolute UV irradiance.

Marine organisms may be adapted to the radiation environment they live in. But humans should keep in mind that the radiation in the tropics is much higher compared to mid latitudes, even under cloudy conditions. However, the data collected on this cruise is in the range of uncertainties desired for UV effects studies. To feasibly investigate UV effects on marine organisms it is desirable to also perform measurements of underwater UV irradiance at various water depths for specific atmospheric conditions.

\section{Conclusions}

In the measurements of spectral UVA, UVB and erythemal irradiance performed on $R / V$ Polarstern, the effect of solar zenith angle, clouds and total ozone column is detected in the daily doses of erythemal irradiance as well as in midday UVA and UVB integrals.

As long as the minutely mean of the ship's pitch and roll is less than $2^{\circ}$ the deviation in erythemal irradiance incident on the tilted sensors is less than $1 \%$ compared to a perfectly horizontal surface. This condition has been fulfilled for more than $95 \%$ of the measured spectra during the north-south Atlantic transect.

It can be advised that it is important to find the most suitable spot for setting up the radiation detectors on the ship. On some ships, it may not be possible to find a suitable location at all. The ideal set-up spot should have minimal obstructions in the sensors' field of view and should be well protected from sea spray. To account for the influence of the ship's superstructures, small broadband sensors, such as the ELUVs, could be placed in different locations on the ship.

The measurements of UV irradiance performed on $R / V$ Polarstern in 2005 indicate already the feasibility to perform ship-borne radiation measurements. The maximum daily dose of erythemal irradiance of $5420 \mathrm{~J} \mathrm{~m}^{-1}$ was observed on 14 November 2005, when the ship was in the tropical Atlantic south of the equator. The expected UV maximum should have been observed with the sun in the zenith during local noon (11 November). Stratiform clouds reduced the dose to $3835 \mathrm{~J} \mathrm{~m}^{-1}$. In comparison, the daily erythemal doses in the mid-latitudinal Bay of Biscay only reached values between 410 and $980 \mathrm{~J} \mathrm{~m}^{-1}$ depending on cloud conditions. The deviation in daily erythemal dose derived from different instruments is around $5 \%$. However, to obtain statistically significant results, a larger data set especially with cloud free conditions is necessary. Data collected on the northsouth Atlantic transect with $R / V$ Polarstern indicate that at least daily doses of erythemal and noon time UVA and UVB irradiance can provide the basis for studies investigating the effect of UV radiation on marine organisms.

\section{References}

1 Environmental Effects Assessment Panel, United Nations Environment Programme, Environmental effects of ozone depletion and its interactions with climate change: Progress report, 2005, Photochem. Photobiol. Sci. 2006, 5, 13-24.

2 J. Bischof, C. Wiencke, in Warnsignale aus den Polarregionen, ed. J. L. Lozan, H. Graß1, H.-W. Hubberten, P. Hupfer, L. Karbe and D. Piepenburg, Wissenschaftliche Auswertungen, Hamburg, 2006, ch. 5.3 , pp. $260-264$.

3 The Effects of UV Radiation in the Marine Environment, ed. S. de More, S. Demers and M. Vernet, Cambridge University Press, Cambridge, 2000, $324 \mathrm{pp}$

4 M. Y. Roleda, D. Hanelt and C. Wiencke, Growth and DNA damage in young Laminaria sporophytes exposed to ultraviolet radiation: implication for depth zonation of kelps on Helgoland (North Sea), Marine Biol., 2006, 148, 1201-1211.

5 C. Wiencke, M. Y. Roleda, A. Gruber, M. N. Clayton and K. Bischof, Susceptibility of zoospores to UV radiation determines upper depth 
distribution limit of Arctic kelps: evidence through field experiments, J. Ecol., 2006, 94, 455-463.

6 R. T. Pinker, B. Zhang and E. G. Dutton, Do Satellites Detect Trends in Surface Solar Radiation?, Science, 2005, 308, 850-854.

7 A. Vasilkov, N. Krotkov, J. Herman, C. McClain, K. Arrigo and W. Robinson, Global mapping of underwater UV irradiances and DNAweighted exposures using Total Ozone Mapping Spectrometer and Seaviewing Wide Field-of-view Senosor data products, J. Geophys. Res., 2001, 106, 27205-27219.

8 A. Arola, S. Kalliskota, P. N. den Outer, K. Edvardsen, G. Hansen, T. Koskela, T. J. Martin, J. Matthijsen, R. Meerkötter, P. Peeters, G. Seckmeyer, P. C. Simon, H. Slaper, P. Taalas and J. Verdebout, Assessment of four methods to estimate surface UV radiation using satellite data, by comparison with ground measurements from four stations in Europe, J. Geophys. Res., 2002, 107, ACL11-1-ACL11-11.

9 T. Hanken and H. Tüg, Development of a Multichannel UVSpectroradiometer for Field Measurements, Environ. Sci. Pollut. Res., 2002, 4, 35-39.

10 S. Wuttke, G. Seckmeyer, O. Schrems and G. König-Langlo, Radiation Measurements at the German Antarctic Neumayer Station, in Ultraviolet Ground-and Space-based Measurements, Models and Effects V, ed. G. Bernhard, J. R. Slusser, J. R. Herman and W. Gao, Proc. of SPIE, 2005, vol. 5886, pp. 588608-1-588608-10, DOI: 10.1117/12.616352.

11 G. Bernhard and G. Seckmeyer, Uncertainty of measurements of spectral solar UV irradiance, J. Geophys. Res., 1999, 104, 1432114345.

12 H. Slaper, H. A. J. M. Reinen, M. Blumthaler, M. Huber and F. Kuik, Comparing ground-level spectrally resolved solar UV measurements using various instruments: A technique resolving effects of wavelength shift and slit width, Geophys. Res. Lett., 1995, 22, 2721-2724.

13 G. Bernhard and G. Seckmeyer, New Entrance Optics for Solar Spectral UV Measurements, Photochem. Photobiol., 1997, 65, 923-930.

14 S. El Naggar, H. Gustat, H. Magister and R. Rochlitzer, An electronic personal UV-B-dosimeter, J. Photochem. Photobiol., B, 1995, 31, 83-86.

15 M. Y. Roleda, C. Wiencke, D. Hanelt, W. H. van de Poll and A. Gruber, Sensitivity of Laminarialeszoospores from Helgoland (North Sea) to ultraviolet and photosynthetically active radiation: implication for depth distribution and seasonal reproduction, Plant, Cell Environ., 2005, 28, 466-479.

16 G. Seckmeyer, A. Bais, G. Bernhard, M. Blumthaler, C. R. Booth, K. Lantz and R. L. McKenzie, Instruments to Measure Solar Ultraviolet
Radiation Part 2: Broadband Instruments Measuring Erythemally Weighted Solar Irradiance, WMO GAW Report No. 164, Geneva, 2005.

17 W. D. Komhyr, Electrochemical concentration cells for gas analysis, Ann. Geophys., 1969, 25, 203-210.

18 WMO (World Meteorological Organization), Strategy for the implementation of the Global Atmosphere Watch Programme (2001-2007), WMO GAW Report No. 142, Geneva, 2001.

19 W. D. Komhyr, R. A. Barnes, G. B. Brothers, J. A. Lathrop and D. P. Opperman, Electrochemical concentration cell ozonesonde performance evaluation during STOIC 1989, J. Geophys. Res., 1995, 100, 9231-9244.

20 U. Köhler, A comparison of the New Filter Ozonometer MICROTOPS II with Dobson and Brewer Spectrometers at Hohenpeissenberg, Geophys. Res. Lett., 1999, 26, 1385-1388.

21 A. I. Kudish, D. Abels and M. Harari, Ultraviolet radiation properties as applied to photoclimatherapy at the Dead Sea, Int. J. Dermatol., 2003, 42, 359-365.

22 S. Wuttke, Radiation Conditions in an Antarctic Environment, Reports on Polar and Marine Research 514, Bremerhaven, Germany, 2005, p. 140.

23 B. Mayer and A. Kylling, Technical note: The libRadtran software package for radiative transfer calculations: Description and examples of use, Atmos. Chem. Phys., 2005, 5, 1855-1877.

24 J. Calbó, D. Pagès and J.-A. González, Empirical studies of cloud effects on UV radiation: A review, Rev. Geophys., 2005, 43, RG2002, DOI: $10.1029 / 2004 R G 000155$.

25 S. Wuttke and G. Seckmeyer, Spectral radiance and sky luminance in Antarctica: a case study, Theor. Appl. Climatol., 2006, 85, 131-148.

26 M. Blumthaler, J. Gröbner, M. Huber and W. Ambach, Measuring spectral and spatial variations of UVA and UVB sky radiance, Geophys. Res. Lett., 1996, 23, 547-550.

27 R. Grant, G. Heisler and W. Gao, Clear sky radiance distributions in ultraviolet wavelength bands, Theor. Appl. Climatol., 1997, 56, 123-135.

28 D. Lubin and E. H. Jensen, Effects of clouds and stratospheric ozone depletion on ultraviolet radiation trends, Nature, 1995, 377, 710-713.

29 G. Seckmeyer, R. Erb and A. Albold, Transmittance of a cloud is wavelength-dependent in the UV-range, Geophys. Res. Lett., 1996, 23, 2753-2755.

30 A. Kylling, A. Albold and G. Seckmeyer, Transmittance of a cloud is wavelength-dependent in the UV-range: Physical interpretation, Geophys. Res. Lett., 1997, 24, 397-400. 